\title{
Methods to Evaluate Airway Resistance and Lung Compliance During Mechanical Ventilation: A Comparative Study
}

\author{
Apoorva S Kulkarni \\ Electronics and Instrumentation Department \\ SJCE, JSS Science and Technology University, Mysuru, \\ India
}

\begin{abstract}
Mechanical ventilation is a lifesaving activity that is used in critical care management. In such case, monitoring of airway resistance $\left(R_{\text {aw }}\right)$ and lung compliance $\left(C_{L}\right)$ play a major role for diagnosing the lung condition, setting the ventilator parameters, can act as a decision parameter for weaning the patient from the ventilator. Several methods have been described for estimating these respiratory parameters. In this work, a study is conducted to compare two different methods used to calculate airway resistance and lung compliance during mechanical ventilation. Michigan Adult/Infant lung simulator is used to simulate different compliance conditions and Michigan Pneuflo Resistors to simulate different resistance conditions. Flow, volume and pressure data were logged for different set parameters i.e. for different resistance and compliance combinations. Later these data were used to calculate the respiratory system resistance and compliance. Two methods were used to calculate lung parameters, dynamic approach and Least Square fitting(LSF) method(using respiratory system equation of motion). Both methods gave accurate estimate of $\mathbf{R}_{\text {aw }}$ and $C_{L}$. But the dynamic approach required respiratory maneuver whereas LSF approach required large datasets to carry out the calculation and the patient should not show any active breathing during evaluation.
\end{abstract}

Keywords:- Mechanical ventilation, Airway Resistance, Lung Compliance, Equation of motion, Least Square Fit, Dynamic approach.

\section{INTRODUCTION}

Millions of people are suffering from lung disorders such as asthma, bronchitis, pneumothorax, Chronic Obstructive Pulmonary Disease (COPD), lung cancer, pneumonia and Acute Respiratory Distress Syndrome(ARDS). Mechanical ventilation plays an important strategy in maintaining the patient with such acute or chronic lung disorder[1][2][3]. Respiration is a process of supplying oxygen to the tissues and removing carbon dioxide from the tissues. When a person is severely injured or ill and cannot breathe on their own, they will need an external support for breathing[3]. An ICU

\author{
Sheela N \\ Electronics and Instrumentation Department \\ SJCE, JSS Science and Technology University, Mysuru, \\ India
}

ventilator is a machine that will assist the patient to breathe under such conditions. ICU ventilators provide artificial ventilation where it supplies right amount of oxygen to the tissues to maintain the desired arterial partial pressure of carbon dioxide (PaCO2) and arterial oxygen tension $(\mathrm{PaO} 2)$. Ventilators are also used during surgeries when the patient is sedated using anesthesia. The purpose of ventilator is mainly to reduce the work of breathing.

To put a patient on to the ventilator, the clinician must have thorough knowledge of physiology of the respiratory system. The decision about selection of ventilation mode and its settings depends on the patient's history, gender, age, pathophysiology, type of the disease and its severity[1].

\section{A. Related work}

Respiratory mechanics refers to the expression of the lung function obtained through measures of pressure and flow. From these mechanics different lung indices can be determined such as volume, resistance, compliance[4]. This paper describes two methods used to calculate airway resistance and lung compliance i.e. dynamic approach and least square fit approach. Apart from these methods other techniques are also available[5][6]. Airway resistance can be calculated in three ways, they are, during inspiration, during expiration and during entire breathing phase[6]. Suter method, Krieger method, Neergard method, Bergman method, Jonson method and Comroe methods are some of the techniques used to calculate airway resistance[6]. In case of lung compliance estimation using equation of motion of the respiratory system, two methods can be used to solve the equation of motion, they are linear regression analysis(LR) and multiple linear regression(MLR) analysis as mentioned in [5]. Nikischin $\mathrm{W}$ et al.,[5] also describe a new algorithm for analysis of non-linear P/V relationships (APVNL) and also proved that this algorithm is faster compared LR and MLR analysis. Lung compliance can also be estimated using other techniques such as inspiratory pause method, multiple inspiratory pause procedures, pulse method, slow inflation-deflation method and interrupt technique during a passive expiration method, which are described in [7]. 


\section{RESPIRATORY MECHANICS}

\section{A. Compliance}

Compliance in simple words is the measure of stretchability or elasticity of the lungs. It is calculated as change in volume $(\Delta \mathrm{V})$ divided by change in $\operatorname{pressure}(\Delta \mathrm{P})[1][4]$. It is given by,

$C=\frac{\Delta \mathrm{V}}{\Delta \mathrm{P}}=\mathrm{V}_{\mathrm{T}} /\left(\mathrm{P}_{\text {Plat }}-\mathrm{PEEP}\right) \mathrm{L} / \mathrm{cmH}_{2} \mathrm{O}$

The normal acceptable value for lung compliance is $50-100 \mathrm{~mL} / \mathrm{cmH}_{2} \mathrm{O}[1][4]$. Based on its measurement, it is classified into two types, static and dynamic lung compliance[3][4]. Static compliance gives the lung compliance at fixed volume when airflow is zero and muscles are relaxed. Dynamic compliance involves continuous measurement of lung compliance at each point of rhythmic breathing. Around $65 \%$ of work of breathing is determined by lung compliance. If the lung compliance is low then more work from breathing muscles is required to inflate the lungs and vice versa. In case of emphysema/COPD patients lung compliance is high thus their lung can easily stretch but cannot recoil easily due to airway obstructions. Low compliance can be seen in patients with pulmonary fibrosis or ARDS/atelectasis where lung is very stiff and more pressure is required to inflate the lung thus there is increase in work of breathing[1]. Compliance can also vary according to gender and age and its reference value for men is discussed in $[8]$.

\section{B. Resistance}

Resistance is the opposition or obstruction to airflow during respiration[1][9]. It is the ratio of difference in $\operatorname{pressure}(\Delta \mathrm{P})$ to the flow and is given by,

$$
\begin{aligned}
& R=\frac{\Delta \mathrm{P}}{\dot{\mathrm{V}}}=\left(\mathrm{PIP} \quad-\quad \mathrm{P}_{\text {plat }}\right) \quad / \quad \dot{\mathrm{V}} \quad \mathrm{cmH}_{2} \mathrm{O} / \mathrm{L} / \mathrm{s} \\
& -(2)
\end{aligned}
$$

Inspiratory resistance in ventilated patients should be $<10 \mathrm{cmH}_{2} \mathrm{O} / \mathrm{L} / \mathrm{s}$ and expiratory resistance is more relative to inspiratory resistance[4]. Airway resistance has more dependencies on certain factors such as cross sectional area or diameter of the airway path, flow type i.e. laminar or turbulent. As diameter of the airway decreases, $\mathrm{R}_{\mathrm{aw}}$ increases according to Hagen-Poiseuille equation[1]. Laminar airflow has less resistance but when patient is ventilated with high volume then flow becomes turbulent which varies the resistance. Airway resistance is also dependent on obstructions in the path which may be caused by excess mucous secretion, tumors in the wall of the airway or inflammation in the airway[9]. $R_{a w}$ increases with increase in the obstructions in the airway path.

\section{METHODS}

In this study, Michigan Adult/Infant test lung simulator is used to simulate different conditions of $\mathrm{R}_{\mathrm{aw}}$ and $\mathrm{C}_{\mathrm{L}}$. Airway resistance conditions were simulated using Michigan Pneuflo parabolic Resistor and lung compliance was simulated using lung simulator. Pneuflo resistors of values 5, 20 and 50Rp were used. Lung compliance could be varied from $10 \mathrm{~mL} / \mathrm{cmH}_{2} \mathrm{O}$ to $100 \mathrm{~mL} / \mathrm{cmH}_{2} \mathrm{O}$. Flow, volume and pressure data were collected during ventilation process and the same were used to calculate $R_{a w}$ and $C_{L}$ using two different approaches. Conventional method described by equation (1) and (2) was also implemented and gave exact estimation of $\mathrm{R}_{\mathrm{aw}}$ and $\mathrm{C}_{\mathrm{L}}$ but required pause time(breath maneuver) during inspiratory phase for accurate estimation. The other two approaches that were implemented are, dynamic method that is described in [10] and applying Least square fit approach to the equation of motion of respiratory system.

\section{A. Dynamic method}

In this method [10] lung compliance $\left(\mathrm{C}_{\mathrm{L}}\right)$ is estimated by static approach but airway resistance $\left(\mathrm{R}_{\mathrm{aw}}\right)$ is estimated by dynamic approach using the lung compliance estimation. The values can be estimated both during inhalation as well as exhalation phase. In the proposed work, the algorithm is implemented only during inhalation phase by simulating different ventilator parameters. The equations for calculating $R_{a w}$ and $C_{L}$ is given by,

$\mathrm{C}_{\mathrm{L}}=\left(\mathrm{V}_{\mathrm{e}}-\mathrm{V}_{\mathrm{i}}\right) /\left(\mathrm{P}_{\text {plat }}-\mathrm{PEEP}\right)$

where,

$\mathrm{V}_{\mathrm{e}}$ - Volume at the start of expiration(which is assumed to be equal to volume at the end of inspiration)

$\mathrm{V}_{\mathrm{i}}$ - Volume at the start of inspiration

$\mathrm{P}_{\text {plat }}$ - Plateau pressure which is the proximal pressure measured at the start of exhalation(which is assumed to be equal to proximal pressure at the end of inspiration)

PEEP - Proximal pressure at the start of inspiration

Since $C_{\text {inh }}$ is estimated under zero flow conditions which is the point where inspiration starts and end, it could be considered as static approach[11].

$\mathrm{R}_{\mathrm{aw}}=\left(\mathrm{P}_{\text {prox@maxflow }}-\mathrm{P}_{\text {lung@maxflow }}\right) / \dot{\mathrm{V}}_{\text {max }}$

where,

$\mathrm{P}_{\text {prox@maxflow }}=$ Proximal pressure during inhalation phase when lung flow is maximum

$\dot{\mathrm{V}}_{\max }=$ Maximum flow during inhalation phase

$\mathrm{P}_{\text {lung@maxflow }}=$ Lung pressure when the lung flow is maximum during inhalation phase and is calculated as,

$\mathrm{P}_{\text {lung@maxflow }}=\mathrm{P}_{\text {plat }}-\left[\left(\mathrm{V}_{\mathrm{e}}-\mathrm{V}_{\text {lung@maxflow }}\right) / \mathrm{C}_{\mathrm{L}}\right]$

where,

$\mathrm{V}_{\text {lung@maxflow }}=$ volume during inhalation phase when lung flow is maximum 
Here $\mathrm{R}_{\mathrm{aw}}$ is estimated when the lung flow is maximum thus it is considered to be dynamic approach[3]. As airway resistance depends on the flow in the path, maximum airflow point is considered for calculation. Resistance is high when air flow through resistive path is maximum and vice versa[10]. The study is conducted on different flow pattern. During volume control mode of ventilation, with square flow pattern, the flow remains constant during the entire inhalation phase, thus midpoint of inspiration was considered as the maximum lung flow point in this study. Whereas for other flow patterns i.e. decelerating and accelerating, the maximum lung flow point has to be estimated separately.

\section{B. Least Square Fit Approach}

In this method equation of motion of the respiratory system is considered to compute $\mathrm{R}_{\mathrm{aw}}$ and $\mathrm{C}_{\mathrm{L}}$. Equation of motion gives the relationship between the time course of one or more variables and the physical state of the system it belongs to[11]. The equation of motion of the respiratory system gives relationship between pressure in the system, flow and volume[12][13]. The equation indicates that at each point in time, the pressure in the respiratory system has an elastic component required for distension of lung parenchyma, a resistive component required for the airflow to advance against the resistance and an inertial component which is considered to be negligible[11]. The equation of motion of the respiratory system is given by,

$\mathrm{P}=(\dot{\mathrm{V}} * \mathrm{R})+(\mathrm{V} / \mathrm{C})$

where, $\mathrm{P}$ is the airway pressure, $\dot{\mathrm{V}}$ is flow to the lung, $\mathrm{R}$ is airway resistance, $\mathrm{V}$ is volume in lung and $\mathrm{C}$ is the lung compliance. Using least square fit method(LSF) eq(6) was solved to obtain $\mathrm{R}$ and $\mathrm{C}$ values. Here $\mathrm{R}$ and $\mathrm{C}$ were estimated in two different approaches, one by considering the $\operatorname{data}(\mathrm{P}, \mathrm{V}, \dot{\mathrm{V}})$ of entire inspiratory phase and another by considering half of the inspiratory phase data. In second approach, the beginning and end portion of the inspiratory data was eliminated from calculation since they contained noise portion[4][15][16].

Equation (6) can be modified by including a variable offset voltage, PEEP[17]. The equation is given as,

$\mathrm{P}=\left(\dot{\mathrm{V}}^{*} \mathrm{R}\right)+(\mathrm{V} / \mathrm{C})+\mathrm{PEEP}$

In eq(7), PEEP was included as an unknown factor and the least square fit approach was applied to fit R, C and PEEP in eq(7).

\section{RESULTS}

The ventilator parameter settings was varied at every step and $\mathrm{R}$ and $\mathrm{C}$ values were varied using Michigan lung simulator and Pneuflo resistor, to check the accuracy of the estimated $\mathrm{R}$ and $\mathrm{C}$. Test was conducted for different tidal volume $\left(\mathrm{V}_{\mathrm{T}}\right)$, PEEP, $\mathrm{T}_{\text {pause }}$ values, different compliance values that varied from $10 \mathrm{~mL} / \mathrm{cmH}_{2} \mathrm{O}$ to $100 \mathrm{~mL} / \mathrm{cmH}_{2} \mathrm{O}$ and three resistance values 5, 20 and $50 \mathrm{Rp}$ were used for testing. The entire test was done using square, decelerating and accelerating wave flow waveform under volume control ventilation mode.

\begin{tabular}{|c|c|c|}
\hline Methods & $\mathrm{R}(\%)$ & $\mathrm{C}(\%)$ \\
\hline $\begin{array}{c}\text { LSF considering } \\
\text { half of the } \\
\text { inspiratory data }\end{array}$ & 71.68 & 85.96 \\
\hline $\begin{array}{c}\text { LSF considering } \\
\text { full inspiratory } \\
\text { data }\end{array}$ & 69.17 & 79.1 \\
\hline $\begin{array}{c}\text { LSF by } \\
\text { considering PEEP } \\
\text { in the equation }\end{array}$ & 31.08 & 84.7 \\
\hline Dynamic method & 31.23 & 82.81 \\
\hline
\end{tabular}

Table 1:- Accuracy of the algorithms

The compliance estimated using dynamic approach i.e. eq(3) was either underestimated or overestimated when no pause time was given, but accurate estimation was done when sufficient pause time was given so that the lung pressure and the airway pressure attained an equilibrium. The resistance values were deviating from the set values i.e. for $\mathrm{V}_{\mathrm{T}}$ of $500 \mathrm{~mL}$, the algorithm underestimated set $\mathrm{Rp}$ value. This deviation was more in case of decelerating wave flow pattern. As the flow increased through the resistive path, the resistance estimate was accurate thus proving the statement that, 'resistance increases as the flow through the resistive path increases'[10].

The $\mathrm{R}$ and $\mathrm{C}$ estimation using LSF method had a varied results. By considering only half of the inspiratory data for estimation, with increase in PEEP and $\mathrm{T}_{\text {pause }}$ values, $\mathrm{R}$ was overestimated whereas $\mathrm{C}$ was estimated accurately. With increase in $V_{T}$ value more accurate estimation was obtained. In the second case where complete inspiratory data was considered for estimation, for higher resistance values, $\mathrm{R}$ was overestimated and $\mathrm{C}$ was underestimated and for lower resistance values, with increase in PEEP and $\mathrm{T}_{\text {pause }}$ values $\mathrm{R}$ and $\mathrm{C}$ were overestimated. Thus selecting the data for estimating $\mathrm{R}$ and $\mathrm{C}$ plays an important role in LSF method[5][14][15]. In the other case of LSF method, where PEEP was included as an unknown factor had underestimation of $\mathrm{R}$ and $\mathrm{C}$ estimation was biased and had a dependency on $\mathrm{T}_{\text {pause }}$ value for any combination of ventilator set parameters[16][17]. 
The estimation of $\mathrm{R}$ and $\mathrm{C}$ using dynamic approach had accuracy of less than $60 \%$. Whereas the LSF approach gave accuracy of 70 to $80 \%$.

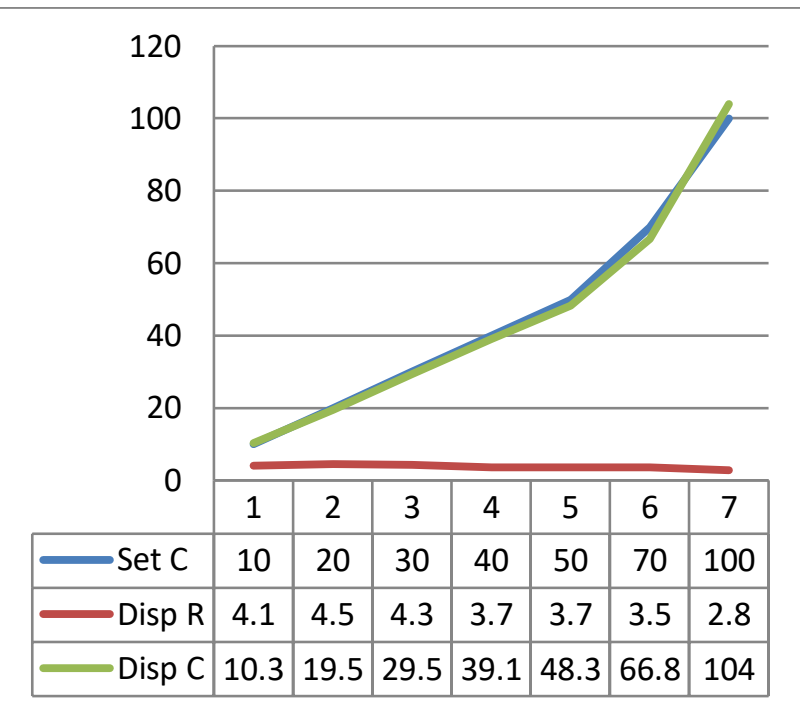

Fig 1:- Estimation of $\mathrm{R}$ and $\mathrm{C}$ (Disp values) with different $C$ values $($ Set $C), \quad V_{T}=350 \mathrm{~mL}$ and $R p=5$ using LSF method (without considering PEEP)

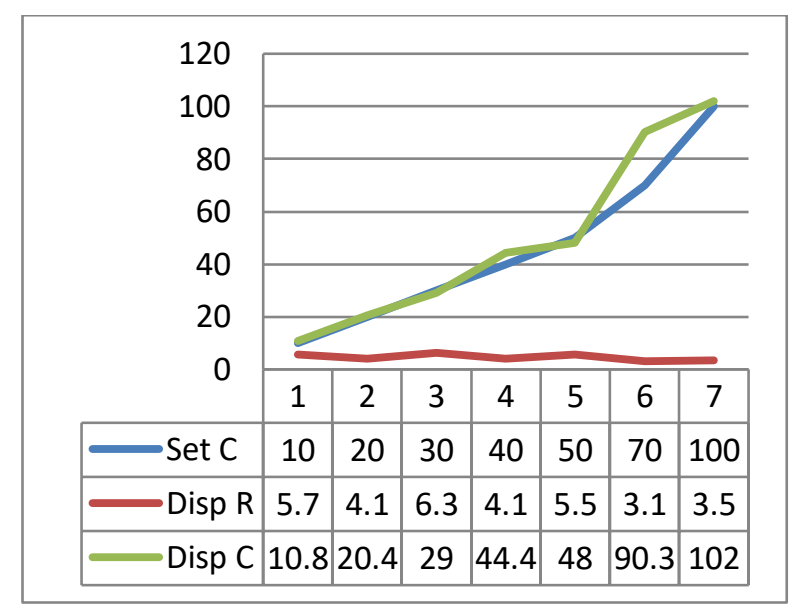

Fig 2:- Estimation of $\mathrm{R}$ and $\mathrm{C}$ (Disp values) with different $C$ values (Set $C$ ), $\quad V_{T}=350 \mathrm{~mL}$ and $R p=5$ using $L S F$ method (with considering PEEP)

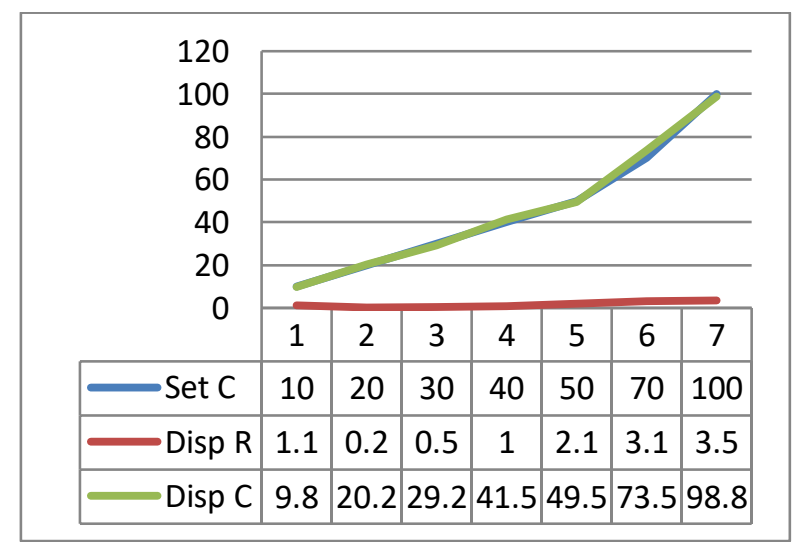

Fig 3:- Estimation of $\mathrm{R}$ and $\mathrm{C}$ (Disp values) with different $C$ values (Set $C$ ), $\quad V_{T}=350 \mathrm{~mL}$ and $R p=5$ using dynamic method

\section{CONCLUSION}

Two different methods used to estimate airway resistance and lung compliance, dynamic approach and LSF method was studied. Both methods gave better estimation, but both methods have certain limitations. In dynamic approach, the estimation required sufficient pause time after inspiration so that the lung would be filled completely with set tidal volume and the pressure values would equalize. The method also indicated lower accuracy in estimating resistance when the flow pattern was changed to decelerating pattern. Whereas, in LSF approach, selecting data for estimation is an important factor. Considering plateau portion of inspiratory data, accurate result was obtained comparing to the estimation done by considering full inspiratory data. This may be due to the instability of the pressure and flow sensors at the beginning and end of inspiration. The LSF approach also requires larger data set for estimation and thus time taken to estimate $\mathrm{R}$ and $\mathrm{C}$ will be long. In future scope, these estimates of $\mathrm{R}$ and $\mathrm{C}$ could be used as decision factor for weaning the patient from ventilator or diagnosing any lung disorder or changing the ventilator parameter settings.

\section{REFERENCES}

[1]. Shevade MS, "Time constant: What do we need to know to use it?" Indian J Respir Care 2019;8:4-7

[2]. Perchiazzi, G., Rylander, C., Pellegrini, M. et al., "Robustness of two different methods of monitoring respiratory system compliance during mechanical ventilation" Med Biol Eng Comput 55, 1819-1828 (2017).

[3]. Henderson WR, Sheel AW, "Pulmonary mechanics during mechanical ventilation" Respir Physiol Neurobiol. 2012 Mar 15;180(2-3):162-72.

[4]. [4] Hess DR, "Respiratory mechanics in mechanically ventilated patients" Respir Care. 2014 Nov;59(11):1773-94.

[5]. Nikischin W, Gerhardt T, Everett R, Bancalari E, "A new method to analyze lung compliance when pressure-volume relationship is nonlinear" Am J Respir Crit Care Med. 1998 Oct;158(4):1052-60.

[6]. Hess D, Tabor T, "Comparison of six methods to calculate airway resistance during mechanical ventilation in adults" J Clin Monit. 1993 Sep;9(4):275-82.

[7]. J van Goudoever, "Determination of total respiratory compliance during artificial ventilation" repub.eur.nl, 890614, 1989.

[8]. Galetke W, Feier C, Muth T, Ruehle KH, BorschGaletke E, Randerath W, "Reference values for dynamic and static pulmonary compliance in men" Respir Med. 2007 Aug;101(8):1783-9. Epub 2007 Apr 6.

[9]. Tomasz Urbankowski, Tadeusz Przybytowski "Methods of airway resistance assesment" DOI:10.5603/PiAP.2016.0014

[10]. Fernando Isaza, "The V680 dynamic respiratory mechanics algorithm". 
[11]. E. García-Prietoa et al., "Monitorization of respiratory mechanics in the ventilated patient" Med Intensiva. 2014 Jan-Feb;38(1):49-55.

[12]. Volta, C.A., Marangoni, E., Alvisi, V. et al., "Respiratory mechanics by least squares fitting in mechanically ventilated patients: application on flowlimited COPD patients" Intensive Care Med 28, 4852 (2002).

[13]. Nikischin W, Gerhardt T, Everett R, Bancalari E, "A new method to analyze lung compliance when pressure-volume relationship is nonlinear" Am J Respir Crit Care Med. 1998 Oct;158(4):1052-60.

[14]. Guttmann, Josef et al., "Maneuver-Free Determination of Compliance and Resistance in Ventilated ARDS Patients CHEST" Volume 102, Issue 4, 1235 - 1242.

[15]. Roussellot JM, Peslin R, Duvivier C, "Evaluation of the multiple linear regression method to monitor respiratory mechanics in ventilated neonates and young children" Pediatr Pulmonol 13:161168(1992).

[16]. Richard R. Uhl, F. John Lewis "Digital computer calculation of human pulmonary mechanics using a least squares fit technique" Computers and Biomedical Research, Volume 7, Issue 5, October 1974.

[17]. Brunner JX, Langenstein H, Wolff G., "A simple method for estimating compliance" Crit Care Med. 1985 Aug;13(8):675-8.

[18]. Huang J, Zhang H, Zhang M, Zhang X, Wang L., "Reference values for resistance and compliance based on the single occlusion technique in healthy infants from Southeast China" J Thorac Dis. 2016;8(3):513-519.

[19]. David A. Kaminsky MD, "What does airway resistance tell us about lung function?" Respiratory Care, January 2012, Vol57 No1.

[20]. Briscoe WA, Dubios AB, "The relationship between airway resistance, airway conductance and lung volume in subjects of different age and body size" Journal Clinical Invest, 1958 Sep;37(9):1279-85. 